\title{
Visibilidad del archivero en el mundo laboral: reflejos de Brasil
}

\author{
Katia Isabelli Melo de Souza*i
}

Resumo: Investigar a visibilidade do profissional de arquivos implica em uma análise do panorama do mercado de trabalho. Em nossa análise consideramos o comportamento de três variáveis determinantes, a formação, as associações profissionais e o mercado de trabalho, em relação aos arquivistas com formação formal. Dessa maneira, a investigação analisou os seguintes aspectos: como o arquivista vê a formação, como vê as associações profissionais e como vê a profissão. Os resultados apontam novos rumos e novas direções aos graduados do curso já que a práxis arquivística extrapolou os limites da Lei 6.546 , de 1978, que regula a profissão, considerando que o arquivista vem criando novos espaços de trabalho e adaptando-se às pesquisas.

Palavras-chave: arquivista; mercado de trabalho; formação; associações profissionais.

Abstract: Investigating the visibility of archivists implies analyzing the employment's landscape. In our analysis we considered the behavior of three key variables, training, professional groups and the labor market, in relation to the archivists with formal training. In this way, the research addressed the following aspects: as the archivist sees training, as an archivist sees the professional groups and as an archivist sees the profession. The results suggest new directions to the graduates and the practice archive has extrapolated the limits of the Law $n \cong 6,546$ of 1978 , which regulates the profession, considering that the archivist has been creating new workspaces and adapting themselves to the research's environment.

Key words archivist; labor market; training; professional groups

Resumen: Investigar la visibilidad del profesional de archivos implica un análisis del panorama laboral. En nuestro análisis consideramos el comportamiento de tres variables determinantes, la formación, los colectivos profesionales y el mercado laboral, en relación a los archiveros con formación formal. De esa manera la investigación analizó los siguientes aspectos: como el archivero ve la formación, como el archivero ve los colectivos profesionales y como el archivero ve la profesión. Los resultados apuntan nuevos rumbos y nuevas direcciones de los graduados del curso ya que la praxis archivística ha extrapolado los límites de la Ley no 6.546, de 1978, que regula la profesión, considerando que el archivero viene creando nuevos espacios de trabajo y encajándose en las investigaciones.

Palabras clave: archivero; mercado laboral; formación; colectivos profesionales 


\section{Introducción}

Según Duchein (1991), la profesión de archivero surgió inicialmente para facilitar el acceso si bien su cometido se ligaba fundamentalmente a la custodia de documentos, no en vano se le conocía como hombre-archivo o archivero-historiador. Su actuación escondida, "detrás" de los archivos, le concedía escasa o ninguna visibilidad. La importancia del trabajo del archivero se aprecia en estas palabras de Peter Horsman: "un archivero no es exactamente un profesional de la información; el trabajo archivístico no es exactamente dar acceso a la información sino dar acceso al registro, a la prueba. Y eso es más que información. Eso es la prueba registrada de las actividades de los organismos públicos o de las organizaciones privadas." (HORSMAN En: BELLOTTO, 2002, p. 48).

Antes de la reglamentación y reconocimiento de la profesión en Brasil, el archivero dejó de ser solamente un conservador teniendo una función dinámica en relación a los documentos (SOARES, 1976). Ya Carol Couture (1998) se les atribuye la responsabilidad de la evaluación de documentos. Otros autores consideran, además, que la participación de los archiveros en el mundo del trabajo, cada día más necesaria hasta hacerse prácticamente indispensable, está asociada al desarrollo socioeconómico (RODRIGUES, 1959), y otros consideran que esa participación se ha expandido (GAGNON-ARGUIN, 1995).

Hoy, en plena sociedad de la información, los archiveros ocupan una posición periférica entre los denominados profesionales de la información, aunque recientemente se les haya incluido en la categoría de gestor de recursos de información (SILVA; RIBEIRO, 2004). Sin embargo, la Profa. Suzane Muller considera que "aunque no haya consenso sobre todas las profesiones que podrían incluirse bajo la denominación de profesionales de la información, podríamos decir que en Brasil bibliotecarios, archiveros y los maestros o doctores en ciencia de la información forman el núcleo de ese grupo" (MULLER, 2004, p. 43). [Traducción nuestra]. En paralelo, Pinto y Ochôa consideran que la misión de los profesionales de la información "es encontrar información (después de haber sabido buscarla), tratarla de modo que se aumenten sus cualidades de uso, generarla, hacerla fácilmente accesible y transmitirla a los que la necesiten, usuarios o clientes. Es lo que hacen los bibliotecarios, documentalistas, archiveros, conservadores y incluso otros." (PINTO; OCHÔA, 2006, p. 40) [Traducción nuestra]. Según el pronóstico de Michael Kohl (1992), el siglo XXI habrá un crecimiento en los servicios de información debido al cual los archiveros ocuparán una posición destacada como profesionales especializados y para eso necesita cultivar la identidad profesional (MYKLAND, 1994). En este sentido, en Brasil se habilita para ejercer la profesión de archivero en los Archivos a profesionales que hayan cursado la graduación en Arquivologiaii, al amparo legal de la Ley no 6.546, de 4 de julio de 1978. 
En esta investigación el panorama laboral, esto es el escenario en el que actúa el principal de los actores de los archivos, el archivero, adquiere preeminencia desde el convencimiento de que la posición de ese profesional en la estructura de la información archivística es central porque es el profesional responsable de la intermediación entre la institución y la búsqueda de la información, entre el usuario y el acervo, entre el documento y la representación de la información.

\section{Antecedentes de la investigación}

La situación de la plantilla de profesionales encargados de la gestión de acervos que se constata en los diagnósticos realizados en archivos públicos brasileños, en particular durante los años 80 y $90^{\mathrm{iii}}$, muestra deficiencias cualitativas y cuantitativas. Esa deficiencia se debe, en parte, a tres factores principales:

1) la escasa presencia de profesionales graduados en Arquivologia procedentes de los cursos que empezaron a surgir a finales de los años 70 en un contexto de reconocimiento de la profesión;

2) pocos órganos contaban con el cargo de archivero en sus plantillas;

3) la práctica ausencia de convocatorias públicas de plazas para archivero.

Las señales más claras del ingreso del archivero en el mercado de trabajo en Brasil se perciben, inicialmente, en los años 90 pero con más intensidad a partir de la década siguiente (SOUZA, 2004) con la publicación de diversas convocatorias públicas de plazas, algo que se ha vuelto más frecuente en estos últimos años gracias a la iniciativa de los gobiernos brasileños.

Con todo, las investigaciones sobre el mercado laboral para el archivero son prácticamente inexistentes en la literatura archivística brasileña. A fin de contribuir a la consolidación de la archivística se hace necesario identificar los espacios de trabajo del área y sus agentes por medio de un análisis en el que se cuente, principalmente, con los recién licenciados.

\subsection{Planteamiento del problema}

\subsubsection{Identificación del problema}

En los últimos años las nuevas tecnologías han transformado los procesos de trabajo y muchas actividades se llevan a cabo con el auxilio de las herramientas de informática. Estos cambios han contribuido también al crecimiento y la expansión de la población económicamente activa. En el mundo del archivo no ha sido diferente. 
En las últimas décadas del siglo XX, las investigaciones sobre los archivos se ampliaron, y se convirtieron en objeto de análisis de investigadores y estudiosos en general. Además, los archivos son comúnmente objeto de estudio de los profesionales que desarrollan sus actividades en ellos. Algunos resultados de esas investigaciones sobre los archivos revelan que:

- la información orgánica es su objeto de estudio;

- el número de investigadores en los archivos es reducido todavía;

- la política de información está poco desarrollada en la mayoría de ellos;

- la cuestión de la transmisibilidad de la información es un problema todavía sin resolver;

- hay una tendencia de quiebra del paradigma de los centros como meros lugares de custodia en beneficio de un paradigma más informativo. (RIBEIRO, 2001).

- la actividad profesional de los archiveros adopta como función fundamental la valorización del objeto físico de la información, del soporte, aunque en los últimos años el concurso de la tecnología de la información ha provocado algunas alteraciones en ese sentido.

Los archivos, inicialmente identificados como meros lugares para la custodia de los documentos por el imaginario popular, hoy por hoy son objeto de reportajes de periódicos, principalmente en cuanto a la política de acceso. Sin embargo, las ampliaciones de las discusiones teóricas sobre el hacer archivístico contribuyen significamente a la construcción científica de la archivística. Los cambios en los archivos provocaran y siguen produciendo la creación de nuevos servicios y, además, la reestructuración y adecuación de los antiguos, con actuaciones más dinámicas y preactivas en los archivos. Empero, los reflejos de estos cambios en los archivos y en el desarrollo del ejercicio profesional todavía no se han estudiados en su totalidad.

En 2008, la reglamentación de la profesión de archivero en Brasil completó 30 años. No obstante, el análisis del comportamiento de los archiveros, su perfil, su imagen en la sociedad y los reflejos en su ambiente de trabajo son fundamentales para que se conozca el profesional en su totalidad. Luego, el problema principal de nuestra investigación es estudiar el panorama laboral para identificar el grado de la visibilidad del archivero en la sociedad. Por todo el expuesto el problema formulado consiste en: ¿La sociedad en general identifica alguna visibilidad en el trabajo ejecutado por el archivero en el mundo laboral? Para identificar la representación de los archiveros en la sociedad, analizamos su interrelación delante de tres elementos basilares que consideraremos como nuestras variables: 
- la formación profesional representado por los cursos de graduación;

- el asociacionismo representado por los colectivos profesionales;

- el mercado laboral representado por los empleadores y por el prisma de los archiveros.

Entendemos que el archivero, como epicentro, recibe la influencia en su medio de estas tres variables. En un primer momento, su vinculación al mercado laboral se basa, sobre todo, a una agregación de la formación reglada. Luego, en un primer análisis investigamos la existencia o no de una homogeneidad en los currículos de los cursos de formación en Arquivologia. Además, analizamos la interacción de la enseñanza con el ejercicio profesional, o sea, la adecuación de los cursos de formación a las exigencias del mercado laboral y viceversa.

En la segunda variable, analizamos la vinculación del asociacionismo profesional y sus colectivos, con los archiveros y los reflejos en la inserción laboral. Al mismo tiempo se estudiaron las implicaciones de esa implicación triple entre colectivos, profesionales y praxis archivísticas impuestas por el mercado. Como complemento, investigamos las prioridades de las atribuciones y en qué momento las asociaciones establecen diálogos con el mercado.

Los empleadores y los requisitos impuestos a los puestos de trabajo para los archiveros constituyen la tercera variable. El punto clave fue analizar cómo viene absorbiendo el mercado a los profesionales y el impacto que ha tenido en los licenciados. Además, analizamos el papel desarrollado por los archiveros en su ambiente de trabajo.

\subsubsection{Hipótesis}

La ampliación del círculo de actuación de los archiveros tiene como elemento basilar el fortalecimiento de su formación para alcanzar mayor visibilidad y su reconocimiento en todos los niveles de la sociedad. En tanto más amplio y rico sea su panorama laboral mayor será su visibilidad social.

\subsection{Finalidad y objetivos}

\subsubsection{Objetivo general}

Analizar la evolución y el comportamiento del mercado de trabajo para archivero en Brasil como espacio de desarrollo de las praxis archivísticas y de la visibilidad del profesional en la sociedad. 


\subsubsection{Objetivos específicos}

- Identificar el proceso de inserción laboral de los archiveros en el mercado;

- Identificar las tendencias que han favorecido la ampliación del mercado de trabajo;

- Analizar la interrelación de los colectivos profesionales con el mercado laboral;

- Investigar la praxis archivística más frecuente desarrollada por los archiveros;

- Analizar la trayectoria de los cursos de formación en Arquivologia en Brasil y su reflejo en el mercado laboral;

- Identificar los espacios de trabajo ocupado por los archiveros;

- Identificar los nuevos frentes de trabajo para el archivero;

- Identificar el grado de calificación profesional exigido en el mercado laboral;

- Analizar el papel de los archiveros según la visión de los empleadores;

- Determinar el índice de impacto obtenido por las demandas presentadas por el mercado;

- Identificar el grado de visibilidad del archivero en el mercado laboral.

\subsection{Justificación: interés y originalidad de la investigación}

La investigación tuvo como objectivo profundizar en el análisis del archivero en Brasil con el concurso de otros agentes que están involucrados en su actuación. La originalidad de la investigación apunta que el principal objeto de análisis es el escenario del archivero en paralelo con los agentes que componen el trípode para su reconocimiento en toda la sociedad, la formación, los colectivos profesionales y el mercado laboral.

Al profundizar la investigación sobre los archiveros encontramos estudios del mercado laboral para los profesionales de la información, sobre todo bibliotecarios y documentalistas (PINTO; OCHÔA, 2006) mientras que los de archiveros todavía son escasos, principalmente en Brasil. En ese país, algunas de las instituciones públicas reconocen el papel crucial que tiene que desempeñar el archivero en la gestión de informaciones orgánicas. Además, se han ampliado las oportunidades en el mercado de trabajo para este profesional y el reconocimiento de sus atribuciones empieza a mostrar un avance significativo, principalmente en la última década.

El ejercicio profesional del archivero en Brasil no cuenta con un órgano fiscalizador, aunque algunas de las asociaciones cumplan el papel de identificar las convocatorias que quedan fuera de los padrones y que, además, rehúyan las atribuciones o requieran otros profesionales para el ejercicio de la archivística. Actualmente existen nueve asociaciones 
profesionales donde los archiveros pueden ascender como miembro del movimiento asociativo.

Con relación a la formación, de una manera un tanto tímida, la evolución de los espacios de enseñanza empezó a ocurrir hace menos de 10 años. Hasta noviembre de 2009 contamos con 16 cursos en total, de los cuales 13 eran de universidades federales y 3 de estatales. Considerando las dimensiones geográficas de Brasil, el número de los cursos y de los licenciados todavía son reducidos. No obstante, Brasil es uno de los pocos países que promueve cursos específicos de formación en la graduación. Aunque existan diferentes tipos de formación en varios países para capacitar a los profesionales en el manejo de los archivos, la archivística sigue siendo un área que necesita un mayor reconocimiento de la sociedad que incluya a sus profesionales, los archiveros. Así, Swift destaca que

... Sin embargo, es solamente el archivero quien preserva la evidencia del pasado en tanto que maneja archivos que contienen anotaciones de actividades pasadas, la evidencia de lo que realmente sucedió, y no simplemente el recuerdo de cualquiera o su interpretación de los hechos que tuvieron lugar en el pasado. Este papel único del archivero le atribuye su relevancia en la sociedad moderna, y aquellos de nosotros que somos miembros de la profesión tenemos la obligación de asegurarnos de que este papel y su importancia es comprendido tanto por los ciudadanos como por los gobernantes. (SWIFT, 1994, p. 14, 15).

Al abordar la cuestión de la investigación y de la formación para los archiveros, MartínPozuelo (2004) presenta tres puntos que, según la autora, poseen estrecha relación con la praxis: la identidad, la visibilidad y la formación de esos profesionales. Analizar a los profesionales que actúan, organizan, manejan y pone a disposición de los usuarios la información de los archivos requiere un nivel de detalle sobre la proyección de ese trabajo para la sociedad en general. Además, añade esta autora:

Para que esta disciplina (Archivística) pueda ser reconocida por su relevancia política, social y económica debe empezar por defender un profesional al que no podemos definir solo por sus funciones si no también por sus responsabilidades, muy relacionadas de acuerdo con esta definición con la satisfacción de demandas muy concretas de la sociedad, de la cultura, la ciencia y la economía de un país. (MARTínPOZUELO, 2004, p. 6).

En 2006, en una encuesta publicada en la Revista Arquivistica.net, en la Web, Jardim destaca la necesidad de estudios sobre el mercado laboral para los archiveros. Según él,

Nosotros necesitamos más conocimiento, no solamente acerca de quiénes somos y cómo estamos en la formación, sino también respecto a quiénes somos y cómo estamos en el mercado de trabajo, 
quiénes somos y cómo estamos en términos de producción y difusión del conocimiento. Nosotros no tenemos hoy una producción de conocimiento sistematizada a propósito del campo profesional en Brasil. (JARDIM En: CARDOSO, 2006, p. 15). [Traducción nuestra].

En vista de la demanda creciente que se revela en el mercado laboral, pasamos a analizar el perfil del profesional que viene ingresando en las instituciones promotoras de las convocatorias públicas de plazas para archivero. ¿Quiénes son? ¿Qué hacen? ¿Cuáles son las atribuciones inherentes a este profesional? ¿Dónde, cuándo y cómo ejercen su actividad? ¿Cuál es la remuneración media que perciben? ¿Cómo se produce el ingreso de estos profesionales en las instituciones que carecen de archiveros? ¿Qué actividades desarrollan? Según Teichler,

... debe compilarse información, con ayuda de las encuestas a graduados o con métodos alternativos, sobre los planes de estudios y las condiciones de estudio en general, y estos datos deben utilizarse en análisis multivariantes que pretendan examinar el impacto de la universidad en la trayectoria profesional de los graduados. (TEICHLER, 2003, p. 24).

De esta manera, analizar y reflexionar acerca de la actuación del archivero en el presente siglo nos permitirá constatar si ha habido cambios en relación en la representación que tiene la sociedad de este profesional.

En el desarrollo de la investigación fueron adoptados tres diferentes tipos de fuentes, a saber: Fuentes de información de carácter legal, basicamente la legislación archivística brasileña; Fuentes de información de carácter bibliográfico; y Fuentes de información directa siendo los cuestionarios y las entrevistas.

\subsection{Metodología}

Para el desarrollo de la investigación hemos recurrido y combinado dos grupos de técnicas: cuantitativas por un lado y cualitativas por el otro. Según Pierre Naville (1973), los instrumentos de observación directa $\mathrm{o}$ indirecta se clasifican en tres categorías: los cuestionarios, las encuestas y los registros, de las cuales se adoptó las dos primeras. La elección de los cuestionarios se justifica por contemplar, al mismo tiempo, una parcela significativa de los profesionales de todo el país y obtener los datos más precisos sobre las cuestiones presentadas. Por su parte, las encuestas presenciales además de respetar un guión preconcebido, posibilitó la indicación de nuevos cuestionamientos a los participantes. 
Para el análisis de todos los datos se recurrió a un paquete de programas estadísticos llamado Statistical Package for the Social Sciences (SPSS), versión 15.0, propio para las investigaciones sociales.

Las fases de la investigación fue estructurada en la siguiente orden: definición de la investigación y revisión de la literatura; identificación del universo objeto de la investigación; diseño de la encuesta para los licenciados; envío del cuestionario; entrevista a los coordinadores de los curso de Arquivologia; entrevista a los Directores de los colectivos profesionales; entrevista a los Empleadores; y análisis de las encuestas.

\subsection{Presupuestos de la investigación}

El estudio exploratorio produjo el esquema vertical izado abajo donde las tres variables presentadas, el mercado, la formación y los colectivos profesionales, serán analizadas en todos los sentidos inversamente proporcionales en función del archivero.

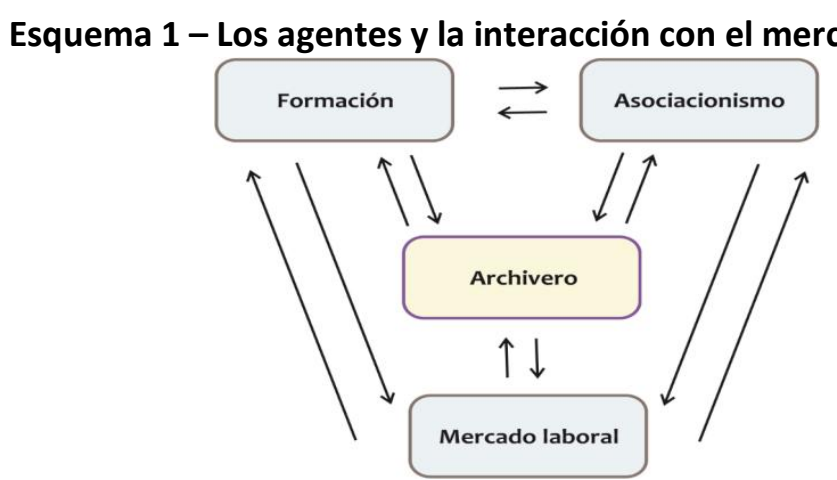

Fuente: Elaboración propia

Los espacios de trabajo presentados por las instituciones formadoras del profesional de archivo son definidos en las diversas categorizaciones de los archivos, sea por el género documental, género audiovisual sea por la naturaleza de los acervos, archivos médicos, de ingeniería y otros. Los cursos de formación en Arquivologia son casi unánimes en definir eses espacios de trabajo. Las perspectivas profesionales para los archiveros, de acuerdo con las unidades formadoras son los archivos eclesiásticos, históricos, fotográficos, contables, y otros fundamentalmente del ámbito público, aunque actúen también en la iniciativa privada y en los acervos personales. Otra parte de los centros de enseñanza a identifican como una profesión nueva y que, consecuentemente, cuenta con un mercado de trabajo en expansión y vislumbran la actuación del profesional, además de los espacios mencionados anteriormente, como investigador, en la reconstitución de la memoria social. Además, se observa que las instituciones formadoras abordan, con mayor amplitud, las funciones archivísticas asociadas a la gestión documental en la gerencia de los más variados soportes y tipologías documentales. 
Los aspectos concernientes a la difusión de los acervos, los productos elaborados, la cuestión de la investigación archivística y los usuarios revelan, aún, poca relevancia.

\section{Universo investigado: los archiveros de Brasil}

Para el conocimiento de ese universo se investigaron los datos de los profesionales titulados de los cursos de Arquivologia hasta el año de 2008. Los datos obtenidos hasta hoy son parciales. Un primer muestreo fue presentado por el Prof. José Ma Jardim en 1992. En su cómputo señalaba que Brasil tenía 1.018 archiveros titulados de los tres primeros cursos de Arquivologia, distribuidos así: 551 procedentes de la Uni-Rio, 245 de la UFSM y 222 de la UFF. (JARDIM, 1992). Tiempo después, a lo largo de un periodo de 20 años, la cantidad de archiveros fue creciendo y alcanzó una proyección de en torno a 3.000. (JARDIM, 2002). Recientemente, el Prof. André Lopez elaboró un estudio prospectivo de los titulados de los cursos en el cual el total de los archiveros en Brasil sumaba 6.138 profesionales hasta 2007. (LOPEZ, 2008).

Con objeto de encontrar nuevos indicadores de los archiveros en Brasil y así presentar con mayor precisión el cómputo general hicimos un análisis de las estadísticas publicadas por el Ministerio de Educación, en la cuales se registran anualmente los cursos de graduación impartidos en las universidades públicas. Los datos reflejan semestralmente las matriculaciones y el número de licenciados, los cursos que presentaban el mayor índice de candidato/plaza ${ }^{\mathrm{iv}}$ y el surgimiento de nuevos cursos. A pesar de estas aportaciones hay una gran laguna en los años 80 y parte de los 90 debido a la ausencia de datos oficiales de dicho período, en el cual se contaba con un número reducido de cursos de Arquivologia. Los datos oficiales indican que en Brasil existen 3644 archiveros con formación formal.

\subsection{El registro profesional de los archiveros}

En Brasil se reconoce el ejercicio laboral legal a los profesionales que cuentan con formación superior, además del registro en los consejos de la categoría. La creación del Consejo Profesionalv de los archiveros fue propuesta en el Proyecto de la ley de reglamentación de la profesión, pero el proyecto fue aprobado sin que se hubiera constituido el órgano. (ESPOSEL, 2008). Sin embargo, los archiveros intentaron crear un Conselho Federal de Arquivologia (Consejo Federal de Arquivologia) tres veces, concretamente, en 1996, 2000 y 2004 a iniciativa de las asociaciones profesionales. Dicho consejo tiene como función actuar para fiscalizar el ejercicio profesional y defender la categoría entre otras acciones. Asimismo, la ausencia de un consejo profesional permite que los archiveros efectúen su registro como 
profesionales en el Ministerio de Trabajo y Empleo, de acuerdo con el Decreto no 93.480 del 29 de octubre de $1986^{\text {vi }}$, donde se establece:

Art. 10 - A efectos de reclasificación y del ingreso en las categorías funcionales de Archivero y de Técnico de Archivo del Grupo-Archivo del Servicio Civil del Poder Ejecutivo, se exigirá el registro profesional previsto en el artículo 4으 de la Lei no 6.546, de 4 de julio de 1978.

El índice comparativo de los titulados y de aquellos archiveros con registro profesional muestra una diferencia significativa ${ }^{\text {vii }}$. Al principio, se concedió el registro a los profesionales que habían obtenido la denominación de archivero en cumplimiento de la ley de reconocimiento de la profesión. Sin embargo, la totalización de los archiveros con registro según el Ministerio del Trabajo es de 1377 profesionales.

\section{Implementación de los cursos de arquivologia en Brasil}

Brasil es un país muy grande en todos los aspectos y lógicamente esto se refleja en su división geográfica. Así, está dividido en cinco regiones: norte, nordeste, sur, sudeste y centroeste, donde tenemos la capital, Brasília. A lo largo las últimas cuatro décadas encontramos el nacedero del curso de Arquivologia en Brasil. En la década de los 70 surgieron los tres primeros cursos, periodo en que Brasil estaba bajo la dictadura. En 1978, el mismo año del reconocimiento de la profesión, empezó la realización de cursos de formación formal, que se impartían en la Uni-Rio, en Río de Janeiro, y en la UFSM, Santa María, en el sur de Brasil. En los años 80 hubo una laguna que posibilitó la creación, en los años 90, de cinco cursos. Posteriormente al año 2000 ya contamos con ocho cursos, además de la propuesta para la creación de cursos en la Universidade Federal de Maranhão, en la región Nordeste, y en la Universidade Federal de Pará, región Norte del país.

Tabla 1 - Cursos de Arquivologia del punto de vista geográfico

\begin{tabular}{c|c|c|c}
\hline Región & Estados & $\begin{array}{c}\text { Cuantitativo } \\
\text { de los cursos }\end{array}$ & Universidades \\
\hline Sudeste & 4 & 5 & UFF, UNI-RIO, UFES, Unesp, UFMG \\
\hline Sur & 3 & 5 & FURG, UFSM, UFRGS, UEL, UFSC \\
\hline Nordeste & 9 & 4 & UFBA(2), UEPB, UFPB \\
\hline Norte & 7 & 1 & UFAM \\
\hline Centro-Este & 3 y DF & 1 & UnB \\
\hline \multicolumn{4}{|c}{ Fuente: Elaboración propia }
\end{tabular}

Las mayores concentraciones están en la región Sudeste que ofrece cinco cursos. La región Sur, con tres estados, contribuye con cinco cursos, tres de los cuales radican en el 
mismo estado, Río Grande del Sur. En la región Nordeste de Brasil hay también cuatro cursos, impartidos por dos universidades. En la región Centro-oeste tenemos tres estados y el Distrito Federal pero el curso superior solamente en la Universidad situada en la capital del país, Brasília. Finalmente, en la región Norte, con siete estados, fue creado en 2008, el curso en la Universidade Federal do Amazonas, UFAM, inicialmente con 30 plazas y un índice de candidato/plaza de 3,67 para el ingreso de la primera turma, en el primer semestre de 2009.

Tabla 2 - Surgimiento de los cursos de Arquivologia en Brasil

\begin{tabular}{|c|c|c|c|c|}
\hline $\begin{array}{c}\text { Univers } \\
\text { idad }\end{array}$ & Acto de creación & $\begin{array}{l}\text { Fecha de } \\
\text { creación }\end{array}$ & Reconocimiento & Vinculación \\
\hline $\begin{array}{l}\text { UNI- } \\
\text { RIO }\end{array}$ & $\begin{array}{l}\text { Decreto no } \\
79.329\end{array}$ & $\begin{array}{c}2 \text { de marzo de } \\
1977\end{array}$ & \begin{tabular}{|c|} 
El curso fue \\
trasladado desde \\
el Arquivo \\
Nacional \\
\end{tabular} & $\begin{array}{c}\text { Centro de Ciências } \\
\text { Humanas e Sociais. } \\
\text { Escola de } \\
\text { Arquivologia }\end{array}$ \\
\hline UFSM & \begin{tabular}{|c|} 
Parecer $n^{\circ}$ \\
$179 / 76$, \\
Conselho de \\
Ensino, Pesquisa \\
e Extensão \\
\end{tabular} & $\begin{array}{c}10 \text { de agosto de } \\
1976\end{array}$ & \begin{tabular}{|c|} 
Portaria $n^{\circ}$ \\
076/81, Ministério \\
da Educação e \\
Cultura
\end{tabular} & $\begin{array}{l}\text { Centro de Ciências } \\
\text { Sociais e Humanas }\end{array}$ \\
\hline UFF & \begin{tabular}{|c|} 
Resolução $n^{\circ}$ \\
$73 / 78$, Conselho \\
de Ensino e \\
Pesquisa
\end{tabular} & $\begin{array}{c}28 \text { de julio de } \\
1978\end{array}$ & \begin{tabular}{|} 
Portaria $n^{\circ} 01$, de \\
01/01/1986, \\
Ministério da \\
Educação e \\
Cultura \\
\end{tabular} & $\begin{array}{c}\text { Instituto de Arte e } \\
\text { Comunicação Social. } \\
\text { Centro de Estudos } \\
\text { Gerais. }\end{array}$ \\
\hline UnB & $\begin{array}{c}\text { Resolução no } \\
\text { 032/90, } \\
\text { Conselho } \\
\text { Universitário }\end{array}$ & $\begin{array}{c}25 \text { de } \\
\text { septiembre de } \\
1990\end{array}$ & \begin{tabular}{|} 
Portaria $n$ o 1.297, \\
de 6/10/1995, \\
Ministério da \\
Educação e \\
Desporto \\
\end{tabular} & $\begin{array}{l}\text { Faculdade de Ciência } \\
\text { da Informação, FCl }\end{array}$ \\
\hline UEL & $\begin{array}{c}\text { Resolução } \\
\text { CEPE/CA n. } 112\end{array}$ & $\begin{array}{l}\text { Creación: } \\
\text { 08/10/1997 } \\
\text { Implantación: } \\
\text { 26/02/1998 }\end{array}$ & \begin{tabular}{|c|} 
Decreto de \\
29/11/2002, \\
Ministério da \\
Educação e \\
Cultura \\
Decreto Estadual \\
n.o 6.646, de \\
$28 / 11 / 2002$ \\
\end{tabular} & $\begin{array}{c}\text { Centro de Educação, } \\
\text { Comunicação e Artes. } \\
\text { Departamento de } \\
\text { Ciência da } \\
\text { Informação }\end{array}$ \\
\hline UFBA & \begin{tabular}{|c|} 
Parecer no \\
075/97, Câmara \\
de Ensino de \\
Graduação \\
\end{tabular} & $\begin{array}{c}10 \text { de abril de } \\
1997\end{array}$ & $\begin{array}{c}\text { Portaria no 1864, } \\
\text { publicada no } \\
\text { D.O.U. de } \\
\text { 16/7/2003. }\end{array}$ & $\begin{array}{l}\text { Instituto de Ciência } \\
\text { da Informação }\end{array}$ \\
\hline UFRGS & $\begin{array}{c}\text { Decisão } \\
\text { Conselho } \\
\text { Universitário } \\
\text { no 112/99 }\end{array}$ & $\begin{array}{c}30 \text { de julio de } \\
1999\end{array}$ & \begin{tabular}{|c|} 
Portaria no 2.881 \\
de 13/09/2004, \\
Ministério da \\
Educação e \\
Cultura, e Parecer \\
602/2004 SESU
\end{tabular} & $\begin{array}{l}\text { Faculdade de } \\
\text { Biblioteconomia e } \\
\text { Comunicação }\end{array}$ \\
\hline
\end{tabular}




\begin{tabular}{|c|c|c|c|c|}
\hline UFES & \begin{tabular}{|c|} 
Parecer do \\
Conselho de \\
Ensino, Pesquisa \\
e Extensão
\end{tabular} & $\begin{array}{c}\text { Creación: } \\
\text { 15/07/1999 } \\
\text { Implantación: } \\
\text { 16/07/1999 } \\
\text { Aprobación: } \\
\text { 12/01/2000 }\end{array}$ & $\begin{array}{c}\text { Portaria no 3.458, } \\
\text { de 25/11/2004, } \\
\text { Ministério da } \\
\text { Educação e } \\
\text { Cultura }\end{array}$ & $\begin{array}{l}\text { Centro de Ciências } \\
\text { Jurídicas e } \\
\text { Econômicas. } \\
\text { Departamento de } \\
\text { Ciências da } \\
\text { Informação }\end{array}$ \\
\hline UNESP & $\begin{array}{c}\text { Resolução } \\
\text { UNESP } \\
\text { no 26/2003 } \\
\end{array}$ & $\begin{array}{c}22 \text { de mayo de } \\
2003\end{array}$ & 2006 & $\begin{array}{c}\text { Faculdade de Filosofia } \\
\text { e Ciências }\end{array}$ \\
\hline UEPB & $\begin{array}{c}\text { Resolução } \\
\text { Consuni } \\
\text { no 10/2006 }\end{array}$ & $\begin{array}{l}29 \text { de marzo de } \\
2006\end{array}$ & - & $\begin{array}{l}\text { Centro de Ciências } \\
\text { Biológicas e Sociais } \\
\text { Aplicadas - CCBSA }\end{array}$ \\
\hline UFAM & $\begin{array}{c}\begin{array}{c}\text { Resolução } \\
\text { Consuni } \\
\text { no } 051 / 2008\end{array} \\
\end{array}$ & $\begin{array}{c}2 \text { de febrero de } \\
2008\end{array}$ & - & $\begin{array}{c}\text { Instituto de Ciências } \\
\text { Humanas e Letras }\end{array}$ \\
\hline UFMG & $\begin{array}{c}\text { Parecer da } \\
\text { Câmara de } \\
\text { Graduação } \\
\text { № 304/2008 }\end{array}$ & $\begin{array}{c}2 \text { de mayo de } \\
2008\end{array}$ & - & $\begin{array}{l}\text { Escola de Ciência da } \\
\qquad \text { Informação }\end{array}$ \\
\hline FURG & 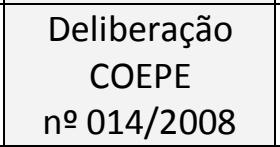 & $\begin{array}{c}16 \text { de mayo de } \\
2008\end{array}$ & & $\begin{array}{c}\text { Instituto de Ciências } \\
\text { Humanas e da } \\
\text { Informação }\end{array}$ \\
\hline $\begin{array}{c}\text { UFBA } \\
\text { (noctur } \\
\text { no) }\end{array}$ & 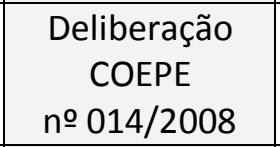 & $\begin{array}{c}16 \text { de mayo de } \\
2008\end{array}$ & - & $\begin{array}{c}\text { Instituto de Ciência } \\
\text { da Informação }\end{array}$ \\
\hline UFPB & \begin{tabular}{|c|} 
Resolução \\
Conselho \\
Superior de \\
Ensino, Pesquisa \\
e Extensão \\
no $41 / 2008$ \\
\end{tabular} & $\begin{array}{l}15 \text { de julio de } \\
2008\end{array}$ & - & $\begin{array}{l}\text { Centro de Ciências } \\
\text { Sociais Aplicadas }\end{array}$ \\
\hline UFSC & $\begin{array}{c}\text { Resolução CEG } \\
\text { no 021/2009 }\end{array}$ & $\begin{array}{c}26 \text { de agosto de } \\
2009\end{array}$ & - & $\begin{array}{l}\text { Depto de Ciência da } \\
\text { Informação }\end{array}$ \\
\hline
\end{tabular}

Fuente: Elaboración propia

Las asignaturas impartidas en los cursos están inseridas en cuatro segmentos: obligatorias, optativas, prácticas (donde se incluyen la monografía de final de curso) y las actividades académicas complementares, según la radiografía presentada en la Tabla abajo. No obstante, los 16 cursos existentes resultan insuficientes hasta hoy para atender a la inmensa división espacial de Brasil. 
Tabla 3 - Radiografía de los cursos de Arquivologia ${ }^{x}$

\begin{tabular}{|c|c|c|c|c|c|c|c|c|c|}
\hline \multirow[b]{2}{*}{ Curso } & \multirow[b]{2}{*}{ Período } & \multirow[b]{2}{*}{ Plazas } & \multirow[b]{2}{*}{ Mín. } & \multirow[b]{2}{*}{ Máx. } & \multirow[b]{2}{*}{$\begin{array}{c}\text { Obligato } \\
\text { rias }\end{array}$} & \multirow[b]{2}{*}{$\begin{array}{c}\text { Optativas } \\
/ \\
\text { Compleme } \\
\text { ntares }\end{array}$} & \multirow[b]{2}{*}{$\begin{array}{c}\text { Prácticas } \\
\text { curricular } \\
\text { es }\end{array}$} & \multirow{2}{*}{\begin{tabular}{|c|} 
Actividades \\
académicas \\
complement \\
ares
\end{tabular}} & \multirow[b]{2}{*}{ Total } \\
\hline & & & & & & & & & \\
\hline $\begin{array}{l}\text { Uni- } \\
\text { Rio }\end{array}$ & \begin{tabular}{|c|} 
Nocturn \\
0 \\
\end{tabular} & 80 & $8 \mathrm{sem}$ & $\begin{array}{c}12 \\
\text { sem }\end{array}$ & $840 \mathrm{H}$ & $840 \mathrm{H}$ & $\begin{array}{l}360 \mathrm{H} \mathrm{y} \\
\text { TCC } 180\end{array}$ & $180 \mathrm{H}$ & $2400 \mathrm{H}$ \\
\hline UFSM & Diurno & \begin{tabular}{|c|}
24 \\
Vestib \\
6 PEIES \\
\end{tabular} & $6 \mathrm{sem}$ & $\begin{array}{c}10 \\
\text { sem }\end{array}$ & $1725 \mathrm{H}$ & $300 \mathrm{H}$ & $\begin{array}{l}225 \mathrm{H} \mathrm{y} \\
\text { TCC } 120\end{array}$ & $180 \mathrm{H}$ & $2550 \mathrm{H}$ \\
\hline UFF & \begin{tabular}{|c|} 
Matutino \\
Nocturn \\
0
\end{tabular} & 60 & $7 \mathrm{sem}$ & $\begin{array}{c}16 \\
\text { sem }\end{array}$ & $1950 \mathrm{H}$ & $120 \mathrm{H}$ & $350 \mathrm{H}$ & $240 \mathrm{H}$ & $2660 \mathrm{H}$ \\
\hline UnB & $\begin{array}{c}\text { Nocturn } \\
0\end{array}$ & $40 *$ & $7 \mathrm{sem}$ & $\begin{array}{c}10 \\
\text { sem }\end{array}$ & $1650 \mathrm{H}$ & $750 \mathrm{H}$ & $240 \mathrm{H}$ & $60 \mathrm{H}$ & $2700 \mathrm{H}$ \\
\hline UEL & $\begin{array}{c}\text { Nocturn } \\
0\end{array}$ & \begin{tabular}{|c|}
40 \\
anuale \\
$\mathrm{s}$
\end{tabular} & 4 & 5 & $1654 \mathrm{H}$ & $658 \mathrm{H}$ & $272 \mathrm{H}$ & 108 & $2692 \mathrm{H}$ \\
\hline UFBA & Diurno & 45 & $6 \mathrm{sem}$ & $\begin{array}{c}10 \\
\text { sem }\end{array}$ & $2278 \mathrm{H}$ & $119 \mathrm{H}$ & $\begin{array}{c}255 \mathrm{H} \mathrm{y} \\
\text { TCC } 272 \mathrm{H}\end{array}$ & - & $2924 \mathrm{H}$ \\
\hline UFRGS & $\begin{array}{c}\text { Nocturn } \\
0\end{array}$ & 30 & $8 \mathrm{sem}$ & - & $1710 \mathrm{H}$ & $300 \mathrm{H}$ & $\begin{array}{l}300 \mathrm{H} \mathrm{y} \\
\mathrm{TCC} 180\end{array}$ & - & $2490 \mathrm{H}$ \\
\hline UFES & $\begin{array}{c}\text { Vesperti } \\
\text { no/ } \\
\text { Nocturn } \\
0\end{array}$ & \begin{tabular}{|c|}
80 \\
anuale \\
$\mathrm{s}$
\end{tabular} & $7 \mathrm{sem}$ & $\begin{array}{c}12 \\
\text { sem }\end{array}$ & $1530 \mathrm{H}$ & $870 \mathrm{H}$ & - & - & $2400 \mathrm{H}$ \\
\hline Unesp & Diurno & 30 & $8 \mathrm{sem}$ & - & - & - & $\begin{array}{c}252 \mathrm{H} \mathrm{y} \\
\text { TCC }\end{array}$ & - & $2520 \mathrm{H}$ \\
\hline UEPB & $\begin{array}{c}\text { Diurno y } \\
\text { Nocturn } \\
0\end{array}$ & & $9 \mathrm{sem}$ & $\begin{array}{c}14 \\
\text { sem }\end{array}$ & $1782 \mathrm{H}$ & $957 \mathrm{H}$ & - & $132 \mathrm{H}$ & $2871 \mathrm{H}$ \\
\hline UFAM & Matutino & 30 & $8 \mathrm{sem}$ & - & - & - & - & - & $2640 \mathrm{H}$ \\
\hline UFMG & \begin{tabular}{|c|} 
Nocturn \\
0 \\
\end{tabular} & 40 & $8 \mathrm{sem}$ & $\begin{array}{c}14 \\
\text { sem }\end{array}$ & $1800 \mathrm{H}$ & $360 \mathrm{H}$ & $240 \mathrm{H}$ & - & $2400 \mathrm{H}$ \\
\hline FURG & \begin{tabular}{|c|} 
Nocturn \\
0 \\
\end{tabular} & 40 & $8 \mathrm{sem}$ & $\begin{array}{c}16 \\
\text { sem }\end{array}$ & $1348 \mathrm{H}$ & $610 \mathrm{H}$ & $\begin{array}{l}298 \mathrm{H} \mathrm{y} \\
144 \mathrm{TCC}\end{array}$ & - & $2400 \mathrm{H}$ \\
\hline UFBA & \begin{tabular}{|c|} 
Nocturn \\
0 \\
\end{tabular} & 45 & $8 \mathrm{sem}$ & $\begin{array}{c}12 \\
\text { sem }\end{array}$ & $1343 \mathrm{H}$ & $374 \mathrm{H}$ & $\begin{array}{l}306 \mathrm{H} \mathrm{y} \\
272 \mathrm{TCC}\end{array}$ & $150 \mathrm{H}$ & $2445 \mathrm{H}$ \\
\hline UFPB & $\begin{array}{c}\text { Diurno y } \\
\text { Nocturn } \\
0\end{array}$ & 40 & $8 \mathrm{sem}$ & \begin{tabular}{|c|}
15 \\
sem
\end{tabular} & $1140 \mathrm{H}$ & $1320 \mathrm{H}$ & $300 \mathrm{H}$ & - & $2760 \mathrm{H}$ \\
\hline UFSC & Matutino & 60 & $8 \mathrm{sem}$ & - & $2268 \mathrm{H}$ & $468 \mathrm{H}$ & $288 \mathrm{H}$ & $180 \mathrm{H}$ & $3204 \mathrm{H}$ \\
\hline
\end{tabular}

* Siendo 32 plazas universal y 8 plazas cota.

PEIES - Programa de Ingresso ao Ensino Superior; TCC - Trabajo de Conclusión de Curso.

Fuente: Elaboración propia 


\section{Reflejos de Brasil: los archiveros en el mundo del trabajo}

Para mapear todos los archiveros que trabajan en Brasil se recurrió a listados de contactos personales así como a listados de discusiones comunes a la archivística. Otro intento para identificar el universo que se iba a investigar fue el sitio de relaciones Orkut (www.orkut.com $)^{x i}$ y sus comunidades ${ }^{x i i}$ profesionales. Las comunidades de Arquivologia existentes congregan a alumnos, titulados, profesores, profesionales de áreas afines y otros.

Además de realizar búsquedas en los diversos sitios de la Web, una gran parte de las direcciones electrónicas se obtuvo por medio de los archiveros que mantienen contactos con los compañeros de carrera. La encuesta estuvo disponible para los archiveros desde noviembre de 2008 hasta abril de 2009 en la página del cuestionario, http://www.cid.unb.br/arquivista/index.asp. La recogida de datos de la investigación aplicada a los licenciados de los cursos de Arquivologia fue totalmente virtual.

\subsection{Aplicación del cuestionario}

Para obtener los datos de los archiveros que actúan en todo Brasil se envió el enlace del cuestionario a las direcciones electrónicas informadas y se obtuvieron 522 respuestas, de las cuales 10 cuestionarios no tenían información alguna, 14 de ellos contenían información de alumnos cuya previsión de conclusión del curso era en 2009 y 13 cuya previsión era en 2010. Además, 33 presentaban duplicidad de nombres. Contando los primeros titulados que contestaron, de 1978, hasta los graduados del segundo semestre de 2008, se llegó a un total de 452 (cuatrocientos y cincuenta y dos) profesionales, lo que supone un 32,8\%, de los 1.377 archiveros registrados en el Ministerio de Trabajo.

Para lograr un mejor análisis de los datos, repartimos los profesionales en ocho grupos cronológicos: 1978-1981, 1982-1985, 1986-1989, 1990-1993, 1994-1998, 1999-2002, 20032005 y 2006-2008 que resultó en el gráfico abajo. 


\section{Gráfico 1 - Análisis general de la encuesta según los grupos cronológicos}

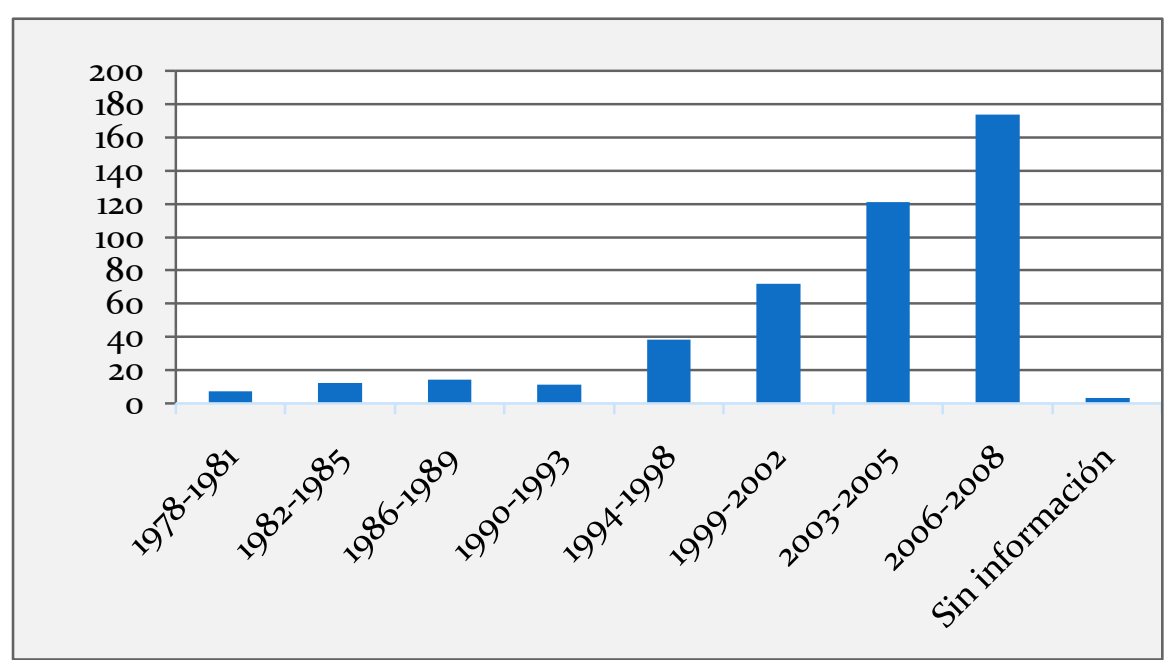

Fuente: Elaboración propia

\subsection{Los archiveros según el sexo}

En todo Brasil se identificaron con mayor frecuencia profesionales de sexo femenino, con un porcentaje del $62 \%$. Lógicamente, los de sexo masculino completaban el total con el $38 \%$ restante.

\section{Gráfico 2 - Archiveros según el sexo}

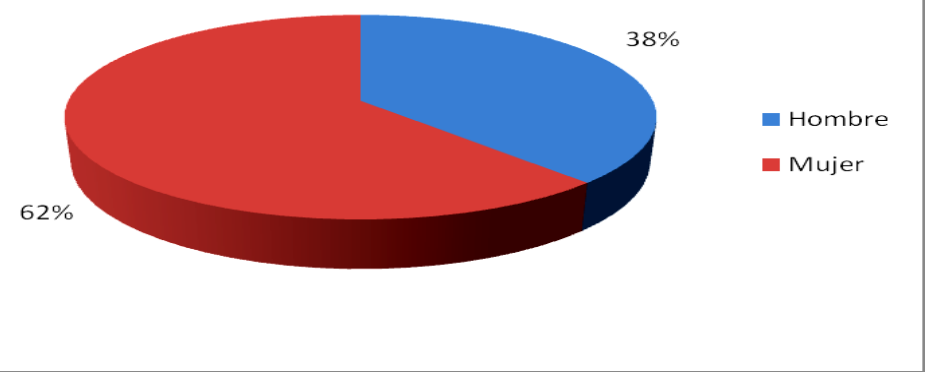

Fuente: Elaboración propia

\subsection{Edad de los archiveros}

La edad de los archiveros presentó algunas variaciones. Para una mejor representación, se agruparon los archiveros en grandes franjas: desde 20 hasta 29 años, desde 30 hasta 39 años, desde 40 hasta los 49 años, desde 50 hasta los 59 años y desde 60 hasta los 69 años. Identificamos que la mayor concentración se da en los profesionales más jóvenes, pertenecientes a la franja de 20 a 29 años. Hubo dos archiveros de la franja 60-69 años y once que no informaron la edad. 


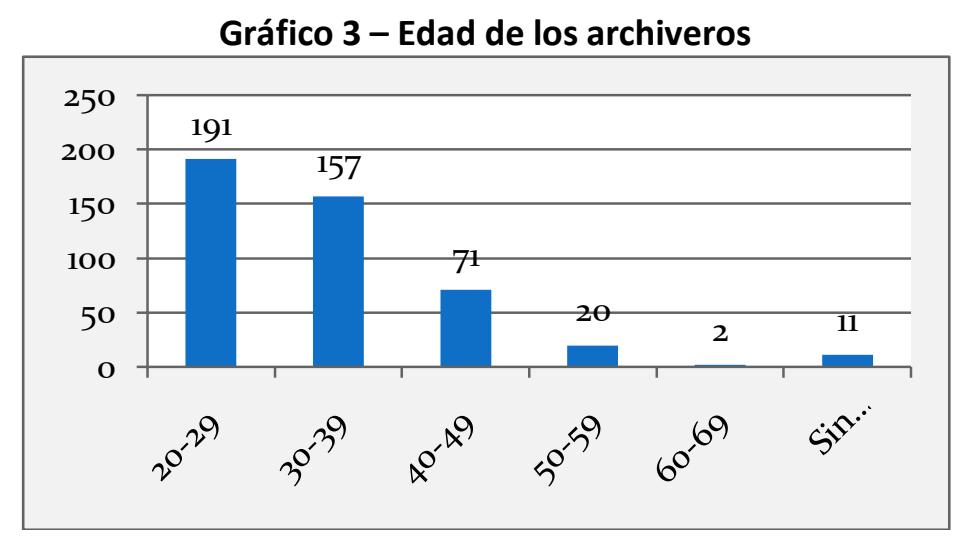

Fuente: Elaboración propia

\subsection{Los espacios de formación}

En Brasil se imparte el curso de Arquivologia en 15 universidades: Uni-Rio, UFSM, UFF, UnB, UEL, UFBA (diurno y nocturno), UFRGS, UFES, Unesp, UEPB, UFAM, UFMG, FURG, UFPB y UFSC. Seis de los cursos fueron creados recientemente y todavía carecen de licenciados. EI mayor índice de respuesta se obtuvo en la UnB, con un total de 172 respuestas. A continuación, siguiendo un orden decreciente, tenemos los dos cursos de Río de Janeiro, UniRio, con 77, y UFF con 61. En la UFSM recibimos respuesta de 56 archiveros, 30 en la UFBA, seguida por la UFES, con 20 , la UEL con 16 , la UFRGS con 14 y, finalmente, la Unesp con seis.

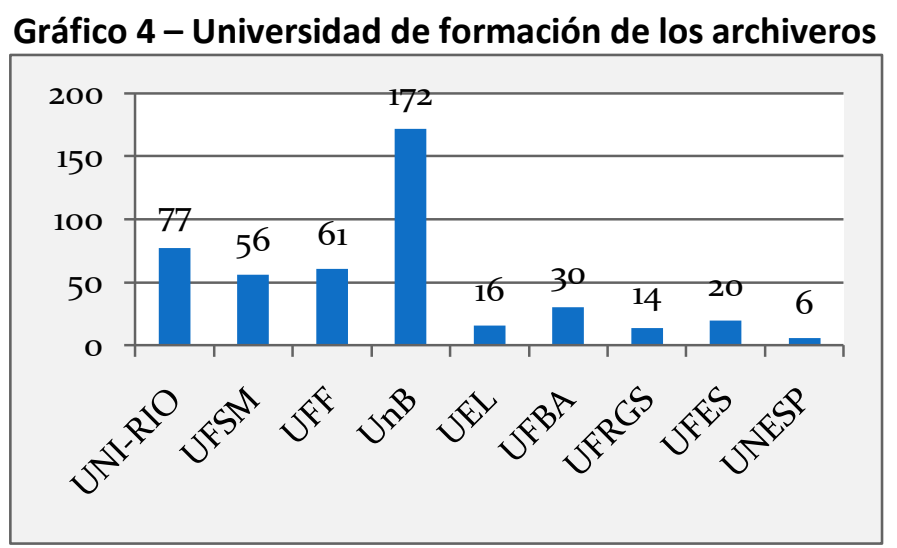

Fuente: Elaboración propia

\subsection{Formación profesional}

En el análisis comparativo, encontramos en todas las regiones una mayor cantidad de archiveros que trabajan. Las universidades de la región sudeste (Uni-Rio, UFF, UFES y Unesp) aportaron un total de 164 archiveros, que en su gran mayoría ejercen la profesión (140, frente a 24 que no trabajan). Por su parte, en el centro-este, únicamente representado por la UnB, se obtuvo el mayor número de respuestas de archiveros (172), con un índice elevado de los que no ejercen, 53 profesionales en comparación con 119 que sí lo hacen. Pertenecen a la región 
sur las universidades UFSM, UFRGS y UEL, con 86 archiveros repartidos entre 61 ejercientes y 25 no ejercientes. De la UFBA, representante de la región nordeste, hay 23 profesionales que trabajan y siete que no. En la región norte, representada por la UFAM, todavía no se han graduado archiveros.

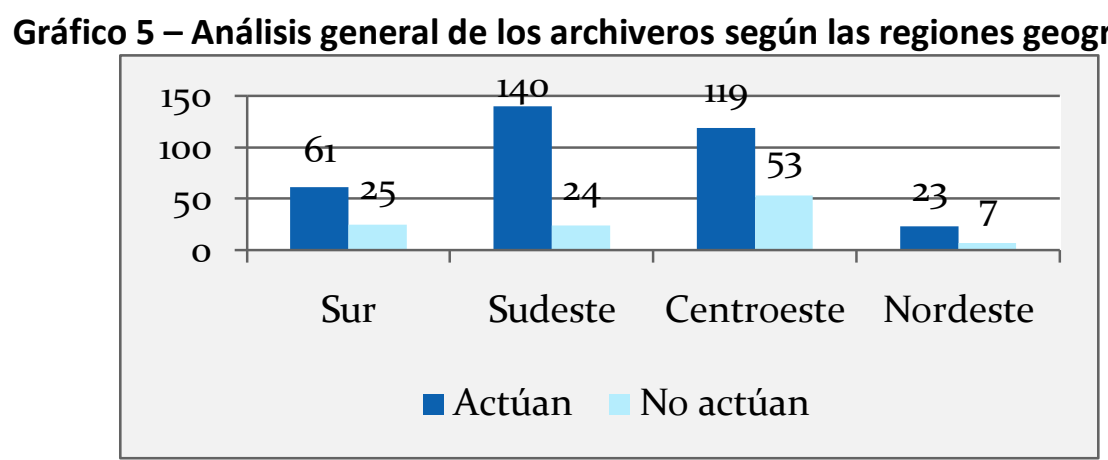

Fuente: Elaboración propia

\subsection{Empleadores y la identificación de los espacios de trabajo}

De las quince instituciones formadoras de archiveros existentes en Brasil, una gran parte presenta una lista similar de espacios de trabajo para archiveros ${ }^{\mathrm{xiii}}$. Además son unánimes en considerar que la profesión es nueva y, consecuentemente, cuenta con un mercado laboral en expansión.

Considerando la posibilidad de que el archivero actúe en más de un frente, los espacios de trabajo fueron registrados 386 veces. De acuerdo con la naturaleza jurídica de las instituciones, el Estado se destaca con claridad como el mayor empleador, dado que un 54\% de los archiveros ejerce actividades en instituciones públicas mientras que un $37 \%$ lo hace en instituciones privadas y un $9 \%$ en otros, sobre todo en ONG.

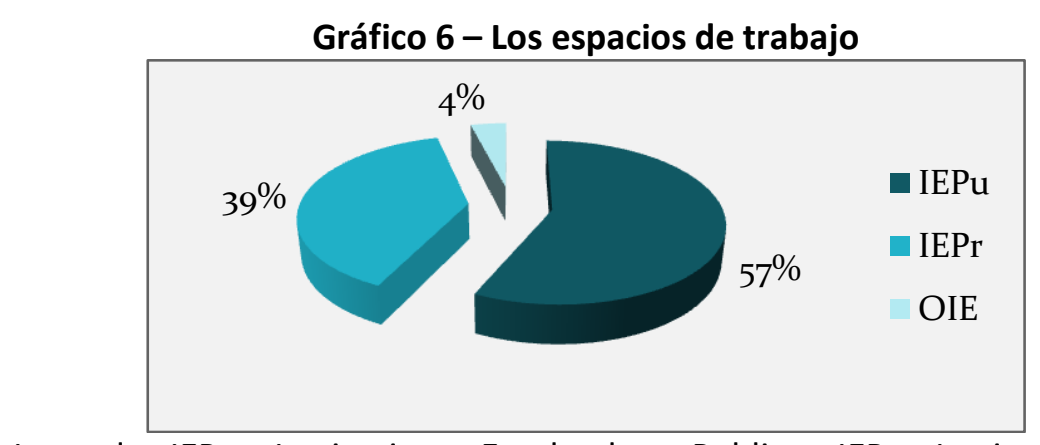

Leyenda: IEPu - Instituciones Empleadoras Publicas; IEPr - Instituciones Empleadoras Privadas; OIE - Otras Instituciones Empleadoras.

Fuente: Elaboración propia

\subsection{Identificando la praxis archivística}

La praxis archivística ejercida por el profesional está asociada a las atribuciones definidas en la legislación, que, comparadas con las propuestas por los teóricos del área, pueden presentar 
ampliación del campo de actuación. Según Angelika Menne-Haritz la actuación de los archiveros

... se puede resumir en la capacidad de hacer accesible una información especial a cada usuario, independientemente de su forma y de la manera en que llegó a apilarla en el archivo. Los documentos medievales $u$ los expedientes modernos son expresiones diferentes de este tipo de información que en el futuro podría presentarse bajo otras formas diferentes. En su análisis final, la definición de la actividad archivística nos conduce a la afirmación de David Bearman, (p. 59) de que el rasgo característico de la profesión de archivista es el manejo de un tipo especial de información, independientemente de la etapa de su desarrollo o del lugar donde se encuentre. La metodología de los archivistas es única dentro de la sociedad de la información. Poseen la clave para muchos problemas del futuro, porque no existen otros especialistas de ese tipo. (MENNE-HARITZ, 1992, p. 60)

Aunque una parte de los titulados cumpla actividades eminentemente técnicas, la mayoría de las veces relativas a documentación acumulada en las instituciones, constatamos que una parte significativa desarrolla actividades docentes, de gestión de proyectos y de dirección de archivos. Las actividades más desarrolladas por los archiveros atañen a la gestión de documentos: clasificación, organización ${ }^{\mathrm{xiv}}$ y selección, con índices muy próximos del 12,7\%, $12,8 \%$ y $12 \%$ respectivamente, además de un margen muy próximo para las actividades de transferencia de documentos, con el 9,2\% y de asistencia técnica, con el 7,9\%. Estos datos indican que el archivero en Brasil actúa con prioridad en la gestión de los documentos. El 7,8\% de los profesionales responsables de la descripción de los documentos señalaron la representación de la información enfocada a los documentos permanentes.

Gráfico 7 - Praxis archivística

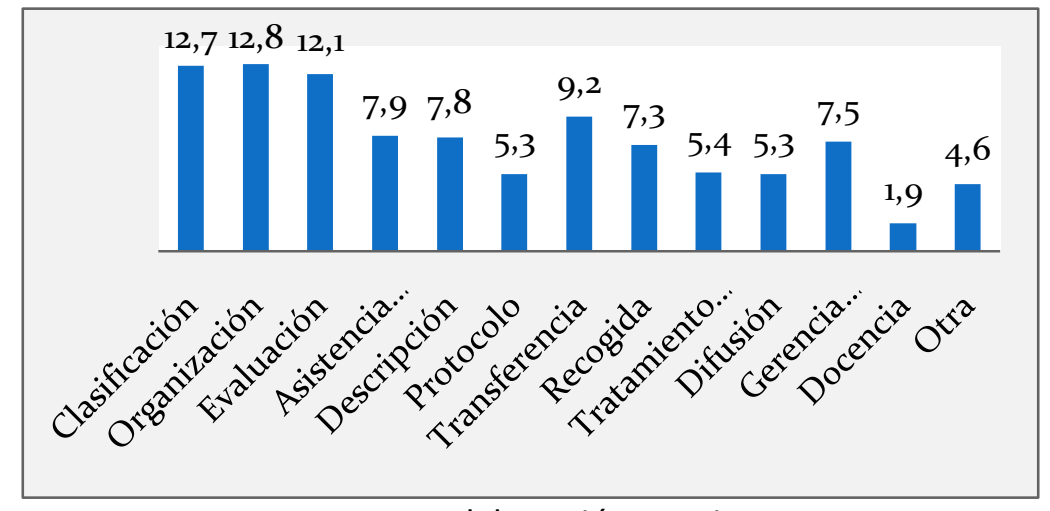

Fuente: Elaboración propia 


\subsection{Política salarial}

En Brasil, el salario mínimo, SM, es un indicador atribuido por la Constitución de la República Federativa del Brasil de 1988, a los trabajadores para garantizar los gastos de una familia "con vivienda, alimentación, educación, salud, ocio, vestuario, higiene, transporte y seguridad social". (Art. 6으, inciso IV). El indicador es la referencia salarial de diversas categorías profesionales. La categoría archivística todavía no dispone de un piso salarial definido nacionalmente. Acerca de la remuneración de los archiveros, la Associação Brasiliense de Arquivologia, Abarq, fue la primera que propuso una indicación para los profesionales archiveros de nivel inicial, posteriormente seguida por otras asociaciones. En la franja con más de 10 SM tenemos 69 archiveros, lo que representa el 17\%; 161, el 32\%, cobran hasta 5 SM, y 110 están en la franja de 6-10 SM. Dejaron de informar la remuneración tres de los archiveros.

\section{Gráfico 8 - Remuneración de los archiveros}

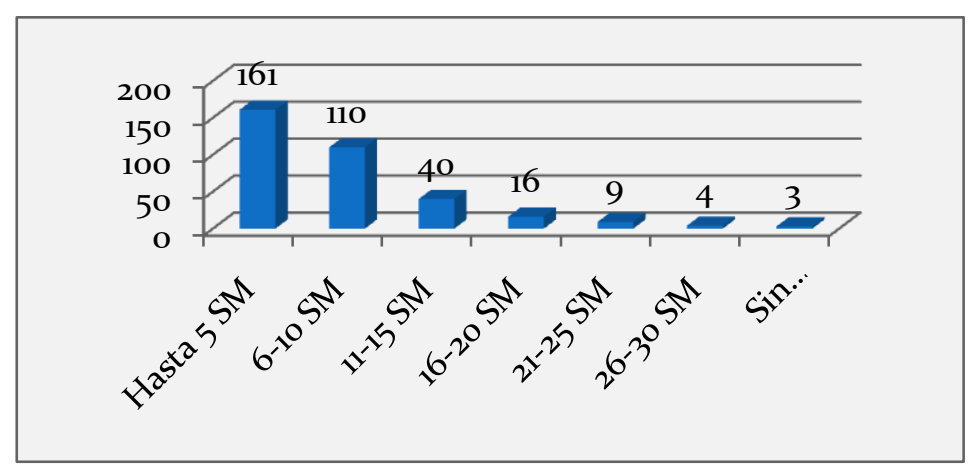

Fuente: Elaboración propia

\subsection{Formación complementar}

La formación continuada ${ }^{\mathrm{xv}}$ es frecuente en los titulados de Arquivologia sobre todo de aquellos que trabajan en el área. Para analizar la formación continuada así como los estudios posteriores a la graduación (incluidos los de posgrado) se recogieron los datos de los profesionales que tienen alguna vinculación, principalmente, con los cursos de posgrado. La participación en los eventos fue sustraída de la cantidad general, aunque se incorporó un campo en la encuesta para indicar la participación en temas de esa naturaleza.

En el cómputo general, comparativamente con los profesionales que ejercen y no lo hacen, los mayores índices son de profesionales que poseen cursos de especialización, con 165 que trabajan y 44 que no lo hacen. A continuación, los archiveros que poseen otra graduación suman 85 de los que trabajan en el área y 30 de los que no. Los índices de mayor diferenciación se dan en la maestría, donde 51 ejercen y 19 no lo hacen. Por último, involucrados con los cursos de doctorado tenemos 24 archiveros que trabajan y 10 que no, tal y como se representa en el siguiente gráfico. 
Gráfico 9 - Formación continuada por campo de actuación

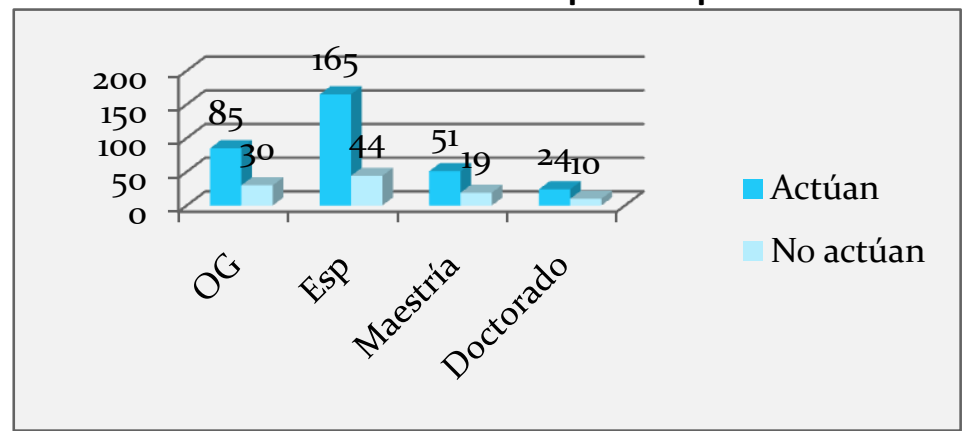

Fuente: Elaboración propia

Según la situación de los estudios, los niveles de la capacitación se clasificaron en tres: concluido, en curso, para aquellos que poseen vínculo con el curso, y no concluido.

\section{Gráfico 10 - Posgrado según la situación del estudio}

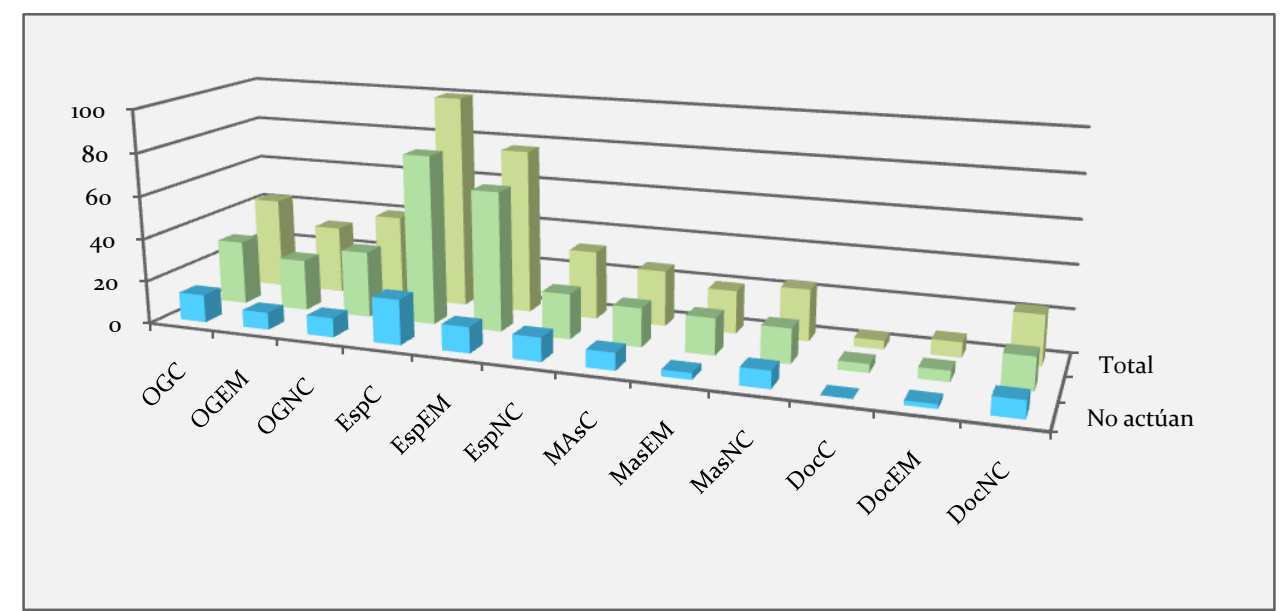

Leyenda: OG-Otra graduación; EspNC-Especialización No Concluida; EspEM-Especialización En Marcha; EspCEspecialización Concluida; MasNC-Maestría No Concluida; MasEM-Maestría En Marcha; MasC-Maestría Concluida; DocNC-Doctorado No Concluido; DocEM-Doctorado En Marcha; DocC-Doctorado Concluido.Fuente: Elaboración propia

Los archiveros se han graduado o están matriculados en cursos de posgrado, especialización, maestría y doctorado, además de revelar dedicación a la investigación científica de la archivística. Incluso, encontramos algunos que poseen doble graduación y doble especialización. Con otra graduación encontramos 105 archiveros. En los cursos de Especialización fue registrada la vinculación de 209 archiveros. En la Maestría tenemos 70 titulados y 34 que cursan o han cursado el Doctorado. Una parte significativa de los profesionales posee otra graduación, la de mayor representación compuesta por 63 mujeres de la UnB. Con especialización concluida tenemos dos índices muy próximos, 15 mujeres de la UnB y 14 de la Uni-Rio. Los mayores índices de la maestría concluida son de cinco hombres de la UnB y de cuatro mujeres de la UFSM. Por su parte, el doctorado ofrece diversidad de 
titulados. El mayor índice de doctorado en curso se da en la Uni-Rio, con dos hombres, la misma universidad que presenta tres hombres con el doctorado concluido.

Tabla 4 - Posgrado según las instituciones de formación, los niveles y el sexo

\begin{tabular}{|c|c|c|c|c|c|c|c|c|c|c|c|c|c|c|c|c|c|c|}
\hline \multirow{2}{*}{$\begin{array}{c}\text { Institu } \\
\text { ciones } \\
\text { forma } \\
\text { doras, } \\
\text { nivele } \\
\text { s y } \\
\text { sexo }\end{array}$} & \multicolumn{2}{|c|}{$\begin{array}{l}\text { Uni- } \\
\text { Rio }\end{array}$} & \multicolumn{2}{|c|}{ UFSM } & \multicolumn{2}{|c|}{ UFF } & \multicolumn{2}{|c|}{ UnB } & \multicolumn{2}{|c|}{ UEL } & \multicolumn{2}{|c|}{ UFBA } & \multicolumn{2}{|c|}{ UFRGS } & \multicolumn{2}{|c|}{ UFES } & \multicolumn{2}{|c|}{ Unesp } \\
\hline & $\mathbf{M}$ & $\mathbf{F}$ & M & $\mathbf{F}$ & $\mathbf{M}$ & $\mathbf{F}$ & $\mathbf{M}$ & $\mathbf{F}$ & M & $\mathbf{F}$ & M & $\mathbf{F}$ & $\mathbf{M}$ & $\mathbf{F}$ & M & $\mathbf{F}$ & M & $\mathbf{F}$ \\
\hline OG & 6 & $\begin{array}{l}1 \\
6\end{array}$ & 4 & $\begin{array}{l}1 \\
8\end{array}$ & 10 & $\begin{array}{l}1 \\
8\end{array}$ & 45 & $\begin{array}{l}6 \\
3\end{array}$ & 3 & 9 & 9 & 7 & 2 & 5 & 2 & 7 & 3 & 2 \\
\hline EspNC & 1 & 1 & - & 1 & - & 1 & 4 & 1 & - & 1 & - & 1 & - & - & - & - & - & - \\
\hline EspEM & 6 & $\begin{array}{l}1 \\
1\end{array}$ & 1 & 9 & 2 & 9 & 13 & 6 & - & 1 & 2 & 7 & 3 & - & 1 & 4 & 1 & - \\
\hline EspC & 8 & $\begin{array}{l}1 \\
4\end{array}$ & 2 & $\begin{array}{l}1 \\
2\end{array}$ & 2 & $\begin{array}{l}1 \\
0\end{array}$ & 8 & $\begin{array}{l}1 \\
5\end{array}$ & 1 & 1 & - & 1 & 1 & 1 & 2 & 2 & - & - \\
\hline $\begin{array}{l}\text { MasN } \\
\text { C }\end{array}$ & 1 & 1 & - & - & 2 & 1 & - & 1 & - & - & - & - & - & - & - & - & - & - \\
\hline $\begin{array}{l}\text { MasE } \\
\text { M }\end{array}$ & 4 & 1 & 1 & 3 & - & - & 1 & 2 & - & - & 1 & 1 & 2 & - & 1 & - & - & - \\
\hline MasC & 2 & - & - & 4 & - & 3 & 5 & 2 & - & - & - & - & - & - & 1 & - & - & - \\
\hline DocNC & - & - & - & - & 1 & - & 2 & 2 & - & - & - & - & - & - & - & - & - & - \\
\hline $\begin{array}{l}\text { DocE } \\
M\end{array}$ & 2 & - & - & 1 & - & 1 & 1 & 1 & - & - & - & - & - & - & - & - & - & - \\
\hline DocC & 3 & - & - & - & - & 1 & - & - & - & - & 1 & - & - & - & - & - & - & - \\
\hline TOTAL & $\begin{array}{l}3 \\
3\end{array}$ & $\begin{array}{l}4 \\
4\end{array}$ & 8 & $\begin{array}{l}4 \\
8\end{array}$ & 17 & $\begin{array}{l}4 \\
4\end{array}$ & 79 & $\begin{array}{l}9 \\
3\end{array}$ & 4 & $\begin{array}{l}1 \\
2\end{array}$ & $\begin{array}{l}1 \\
3\end{array}$ & 17 & 8 & 6 & 7 & 13 & 4 & 2 \\
\hline
\end{tabular}

Leyenda: OG - Otra Graduación; EspNC - Especialización no concluida; EspEM Especialización en marcha; EspC - Especialización concluida; MasNC - Maestria no concluida; MasEM - Maestría en marcha; MasC - Maestría concluida; DocNC - Doctorado no concluido; DocEM - Doctorado en marcha; DocC - Doctorado concluido.

Fuente: Elaboración propia

\subsection{Producción bibliográfica}

La producción bibliográfica más significativa pertenece a los profesionales que están implicados en la formación continuada, o sea, los cursos de especialización, maestría y doctorado. Además de la producción académica, desarrollan investigaciones en el área y 
estudios de casos de sus trabajos con presentación de ponencias en eventos, ya sean congresos, seminarios u otros.

La investigación reveló que 104 archiveros, o sea, 19\% del total, produjeron libros y trabajos, contando participación en publicaciones, elaboración de artículos, conferencias pronunciadas en eventos e impartición de cursos con producción de material didáctico.

\section{Gráfico 11 - Producción bibliográfica}

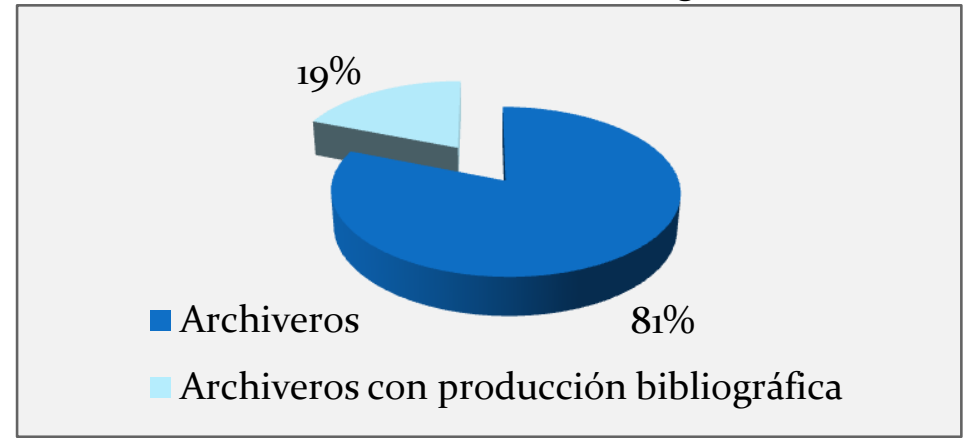

Fuente: Elaboración propia

En la representación gráfica general se constata una evolución ascendente del índice de la producción bibliográfica de los archiveros. Encontramos tres profesionales con producción bibliográfica en cada uno de los dos primeros grupos. Hay que señalar que los archiveros con formación reciente presentaron mayor índice de producción con 36 profesionales, además de 10 archiveros que dejaron de informar el año de formación.

\subsection{El asociacionismo y la afiliación a las asociaciones profesionales}

En el área de información en Francia, el agrupamiento de los profesionales en asociaciones es incluso un vehículo para acceder al mercado de trabajo. Dada la representatividad e integridad de esas instituciones, esos colectivos son responsables de la interacción e integración de los archiveros en los empleos (CUNHA, 1999). En Brasil esa práctica se hizo frecuente en nuestra área más recientemente, con el uso de espacios de divulgación de las ofertas del mercado laboral por medio de algunas asociaciones profesionales y también de las listas de discusión.

Sin embargo, las asociaciones revelaron poca representatividad entre los profesionales, de acuerdo con la encuesta. Con excepción de uno de los archiveros que dejó de informar al respecto, constatamos que más de la mitad de los titulados, 306, están desvinculados del asociacionismo y que hay solamente 145 archiveros afiliados.

Gráfico 12 - Filiación a la asociación profesional - general 


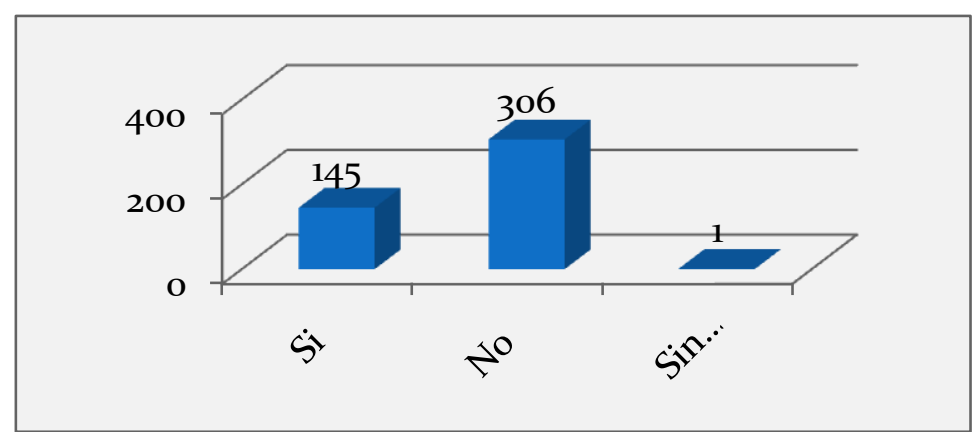

Fuente: Elaboración propia

\subsubsection{Afiliación a las asociaciones profesionales en Brasil}

La vinculación a las asociaciones profesionales es muy dispersa. De los 111 titulados que trabajan, el mayor índice de afiliación procedía de la AARGS, con 24 profesionales, seguida de la Abarq y la AAERJ, ambas con 17 archiveros. Los titulados que no ejercen apuntaron a la Abarq como la asociación profesional representativa en cinco casos, cerca de la AARGS, con cuatro titulados. La mayor representación de afiliaciones en conjunto la tenemos en los cuatro archiveros vinculados a la $A A B$ y la ArqSP.

Tabla 5 - Vinculación del asociacionismo según la actuación

\begin{tabular}{l|c|c}
\hline $\begin{array}{l}\text { Asociación profesional/ } \\
\text { actuación }\end{array}$ & Actúan & $\begin{array}{c}\text { No } \\
\text { actúan }\end{array}$ \\
\hline AAB & 12 & 1 \\
\hline AAB, AAERJ & 2 & - \\
\hline AAB, Abarq & 3 & - \\
\hline AAB, ArqSP & 4 & - \\
\hline AAB, ENARA & - & 1 \\
\hline AABA & 10 & 1 \\
\hline AAERJ & 17 & 3 \\
\hline AAERJ, AAB, ArqSP & 1 & - \\
\hline AAERJ, ENARA & 3 & - \\
\hline AAG & 1 & - \\
\hline AAG, AAB & 2 & - \\
\hline AAPR & 2 & - \\
\hline AARGS & 24 & 4 \\
\hline AARGS, AAERJ & 1 & - \\
\hline AARQES & 8 & 1 \\
\hline AARQES, ENARA & - & 1 \\
\hline Abarq & 17 & 5 \\
\hline Abarq, ENARA & - & 1 \\
\hline ArqSP & 2 & 1 \\
\hline Enara & 2 & 1 \\
\hline & $\mathbf{1 1 1}$ & $\mathbf{2 0}$ \\
\hline \multicolumn{1}{c}{ Total } &
\end{tabular}

Fuente: Elaboración propia 
La mayor representación en una de las asociaciones pertenece a los profesionales procedentes de la UFSM, con 14 mujeres afiliadas a la AARGS. El movimiento asociativo está más presente en la Uni-Rio, con 13 hombres y 15 mujeres que participan en asociaciones. Los titulados de la Unesp no están vinculados a las asociaciones profesionales. Además, constatamos que la ausencia de un órgano que represente a la categoría posibilita el ingreso en más de una asociación sin que ocurran divergencias. Dos titulados dejaron de informar los datos necesarios para incluirlos en la tabla.

\section{Conclusiones}

La información es un instrumento fundamental para el crecimiento, planificación, desarrollo e investigación de las instituciones. Así, los archivos, en cuanto unidad de información, son elementos clave tanto para la toma de decisiones como para el proceso decisorio, toda vez que tienen como función principal organizar y diseminar la información. En este contexto, las actividades del archivero son esenciales para toda organización aunque no tenga el mismo reconocimiento como profesional indispensable. Los recursos destinados a los proyectos de modernización institucional, desarrollo de la plantilla, podrían ser de menor envergadura si hubiese inversión en los archiveros así como en sus tareas operativas y de gestión.

Para conocer la realidad de los archiveros e identificar su visibilidad la investigación se enmarcó en el comportamiento de tres variables determinantes: la formación, los colectivos profesionales y el mercado laboral, en relación a los archiveros con formación formal. El universo investigado contempló desde los primeros graduados que se licenciaron en 1978 hasta los archiveros con titulación obtenida en 2008. La contribución de todos ellos fue fundamental para el examen de los datos, dado que los profesionales más antiguos identificaron las dificultades y las trabas que habían conocido en el mercado laboral. Por otro lado, los más recientes expresaron sus primeras experiencias junto con propuestas y alteraciones para un nuevo diseño curricular, entre otras aportaciones.

Los datos, observados en general, revelan que los 452 archiveros que contestaron están distribuidos por las cinco regiones brasileñas aunque concentrados en Río de Janeiro, Brasília y Río Grande del Sur. El perfil diseñado indica que la mayoría de los 343 archiveros son de sexo femenino, con un $64 \%$ de mujeres en la franja de edad perteneciente al grupo de 20 29 años, con un tiempo de formación de 3-5 años y experiencia en instituciones públicas y una franja salarial de hasta $5 \mathrm{SM}$. Si el archivero presenta tradicionalmente una vocación estatal o pública podemos considerar que hoy por hoy se da una notable participación en otros ambientes, con una proyección significativa de la apertura de otros espacios de trabajo que se 
concreta en una presencia en el $37 \%$ de las instituciones privadas y el $9 \%$ en otros, sobre todo en las ONG.

El cargo ocupado recibe la denominación de Archivero con 40 horas semanales de trabajo y se centra, fundamentalmente, en la gestión de los documentos aunque también ejerce la docencia con la formación de equipos. Los espacios de discursividad creados por las listas de discusión no son representativos y tampoco los indicadores de los colectivos profesionales son expresivos, dado que reflejan un bajo índice de unidad de los profesionales. Con todo, por lo general el profesional conoce el idioma inglés, participa en los eventos del área y publica artículos en los anales.

Con relación a la formación, dos de los cursos de Arquivologia existentes en Brasil, el de la UEL y el de la UFES, realizaron una investigación sobre el mercado laboral para archiveros antes de la implantación de los cursos, que demuestra una correlación formación/mercado laboral. Así, los espacios donde se imparten los cursos es donde surgen con más frecuencia oportunidades de empleo, o sea, se encuentra una mayor demanda del mercado laboral. Hay que tener en cuenta que las oportunidades frecuentes de empleo y con mayor índice de plazas para el archivero sobrepasan el eje Brasília-Río de Janeiro, pensando en las últimas convocatorias de plazas realizadas en las demás regiones de Brasil.

Los colectivos profesionales y los cursos de formación mostraron una tenue aproximación que se concreta, sobre todo, por eventos en colaboración. Con el mercado laboral los colectivos indicaron un mayor acercamiento en función de la divulgación de las ofertas de trabajo aunque el mercado todavía no reconozca a las asociaciones como agentes de difusión y captación de empleos.

Los resultados apuntan nuevos rumbos y nuevas direcciones de los graduados del curso ya que la praxis archivística ha extrapolado los límites de la Ley no 6.546, de 1978, que regula la profesión. De esta manera, el archivero viene creando nuevos espacios de trabajo, además de una participación en las investigaciones. Nuevas atribuciones habrán de ser incorporadas a la legislación a fin de que se constituya un modelo para ser aplicado no sólo en Brasil sino en otros países que impartan los cursos de formación reglados.

La hipótesis inicialmente presentada refrenda que la amplitud del círculo de actuación de los archiveros tiene como elemento basilar el fortalecimiento de su formación para alcanzar su reconocimiento en todos los niveles de la sociedad. Los resultados apuntan que tiene que haber una movilidad entre las tres variables: la formación, la forma de inserción representada por los colectivos profesionales y la producción, simbolizada por el mercado laboral. El archivero como epicentro de esas variables facilita el ingreso del profesional en el mercado 
laboral con índices ascendentes asociados al nivel de visibilidad pero, no obstante, su trabajo necesita ser más conocido todavía, en particular por la sociedad en general.

\section{Referencias}

BELLOTTO, Heloisa L. Os desafios da formação profissional dos modernos arquivistas. Cenário Arquivístico. Abarq, Brasília, v. 1, 2002, p. 47-52. ISSN: 16765605

BORDEN, Víctor M. H. "Las encuestas a egresados universitarios como medio para la mejora de las universidades: lecciones desde Estados Unidos". En: VIDAL GARCÍA, Javier (Coord). Métodos de análisis de la inserción laboral de los universitarios. León : Universidad, Secretariado de Publicaciones y Medios Audiovisuales. 2003.

BRASIL. Ministério da Educação e Cultura. Sinopse Estatística do Ensino Superior - 1990. Brasília, ago. 1991.

BRASIL. Lei 6.546, de 4 de julio de 1978. Dispõe sobre a regulamentação das profissões de Arquivista e de Técnico de Arquivo, e dá outras providências.

CARDOSO, Julio Cesar. "Entrevista con José Maria Jardim". Arquivística net. Rio de Janeiro, v. 2, n. 1, p. 7-21, jan/jun. 2006. Fecha última consulta: 16, 10, 2009. Disponible en: www.arquivistica.net

COMISSÃO ESPECIAL DE PRESERVAÇÃO DO ACERVO DOCUMENTAL - CEPAD. A importância da informação e do documento na administração pública brasileira. Brasília: FUNCEP, 1987.

CUNHA, Miriam Vieira da. "O profissional da informação e o mercado de trabalho". Informação e Sociedade. Florianópolis, $1999 . \quad$ Disponible en: http://www.informacaoesociedade.ufpb.br/IS1010008.htm

DEMO, Pedro. Metodologia científica nas ciências sociais. São Paulo : Atlas. 1995.

DUCHEIN, Michel. "La profesión de archivero entre el pasado y el futuro". Lligall. Revista Catalana d'Arxivística, n. 4, 1991, p. 13-24.

ESPOSEL, José Pedro. Entrevista concedida à Enara. 04 jul. 2008. Disponible en: http://www.enara.org.br/

FUNDACIÓN Histórica Tavera. "Relatório sobre a situação do patrimônio documental brasileiro". Mesa Redonda Nacional de Arquivos. Caderno de textos. Rio de Janeiro: Arquivo Nacional, 1999.

GAGNON-ARGUIN, Louise. "L'évolution historique de la mission de l'archiviste". En: La mission de l'archiviste dans la société: 2e Symposium en archivistique. (Université de Montréal, 8 et 9 avril 1994). Montréal: Groupe interdisciplinaire de recherche en archivistique, 1995, p. 37-49.

JARDIM, José Maria. "A Universidade e o ensino da arquivologia no Brasil". En: Congresso Brasileiro de Arquivologia. (10으, São Paulo, 1992). (Primeira Sessão Plenária) Fecha última consulta: 31,07, 2009. Disponible en: http://www.voy.com/19210/3/152.html

JARDIM, José Maria. "La formación archivística reglada: algunas experiencias en la universidad 
dentro y fuera de España". 2002, 11 p._. Disponible en: http://archivaldo.uc3m.es/seminario/revista_ria/numero_01/01_mesa1.htm

LOPEZ, André Porto Ancona. "O ser e o estar arquivista no Brasil de hoje". En: Congresso Brasileiro de Arquivologia. (15ㅇ, Goiânia, 2008). AAGO. jul. 2008.

MARTíN-POZUELO, M. Paz. "El futuro inmediato de la investigación y la formación en archivística: tres decálogos para el debate". En: Congresso da BAD. (8으, Estoril, 2004). p. 5. Disponible en http://sapp.telepac.pt/apbad/congress08/convidado3.pdf

MENNE-HARITZ, Angelika. "Formación en archivística: satisfaciendo las necesidades de la sociedad del siglo XXI". Foro Archivístico, Mexico, n. 4, jul./dic. 1992. p. 57-74.

MULLER, Suzana. "Uma profissão em evolução: profissionais da informação no Brasil soba ótica de Abbott - proposta de estudo". En : MULLER, Suzana Pinheiro; BAPTISTA, Sofia Galvão (Org.). Profissional da informação: o espaço de trabalho. Brasília : Thesaurus, 2004, (Estudos Avançados em Ciência da Informação. v. 3). p. 23-54.

MYKLAND, Liv. "Protection and integrity: the arquivist's identity and professionalism". Archivum. Paris, CIA. v. 39, 1994, p. 99-109.

PINTO, Leonor Gaspar; OCHÔA, Paula. (Coords.). A imagem das competências dos profissionais de Informação-Documentação: relatório. Observatório da Profissão de InformaçãoDocumentação. 1a ed. Lisboa, 2006. 219 p.

RIBEIRO, Fernanda. "Archival science and changes in the paradigm". Archival Science. v. 1, n. 3, sep. 2001, p. 295-310.

RODRIGUES, José Honório. A situação do Arquivo Nacional. Rio de Janeiro : Ministério da Justiça e Negócios Interiores. 1959. 73 p. Il.

ROUSSEAU, Jean-Yves \& COUTURE, Carol. Os fundamentos da disciplina arquivistica. Dom Quixote, Lisboa, 1998. 357p.

SILVA, Armando Malheiro da; RIBEIRO, Fernanda. "Formação, perfil e competências do profissional da informação". En: Congresso Nacional de Bibliotecários, Arquivistas $e$ Documentalistas. (8.ํ, Estoril, 2004). Nas encruzilhadas da Informação e da Cultura : (re)inventar a profissão : actas, Associação Portuguesa de Bibliotecários, Arquivistas e Documentalistas, Estoril, Lisboa. Cd-rom (2004). Disponible en: http://www.apbad.pt/Edicoes/EdicoesCongresso8.htm

SOARES, Nilza Teixeira. "Publicações Oficiais, Arquivos Impressos". Revista de Biblioteconomia de Brasília. Brasília, v. 4, n. 2, jul./dez. 1976.

SOUZA, Katia Isabelli. "Mercado de trabalho para arquivista". En: Congresso Nacional de Arquivologia. (1으, Brasília, nov. 2004). Abarq, 2004.

SOUZA, Katia Isabelli Melo de. Panorama do mercado de trabalho para arquivista: um enfoque de Brasília. En: FRÍAS, José Antonio; TRAVIESO, Críspulo. Formación, investigación y mercado laboral em información y documentación en España y Portugal. Salamanca, mayo 2008. p. 541551. 
SWIFT, Michael. "El archivo: nuevas tareas, nuevos objetivos". TABULA, n. 3, 1994.

TEICHLER, Ulrich. "Aspectos metodológicos de las encuestas a graduados universitarios". En: VIDAL GARCÍA, Javier (Coord). Métodos de análisis de la inserción laboral de los universitarios. León : Universidad, Secretariado de Publicaciones y Medios Audiovisuales. 2003. P. 15-30.

\section{Notas}

'Resumen de la tesis "Análisis y evolución del panorama laboral del archivero en Brasil: el Poder Legislativo Federal en escena" presentada en la Universidad Carlos III de Madrid. Jul. 2010.

* Profesora del curso de Arquivologia, Universidade de Brasília. Email: isabelli@unb.br

ii De aquí en adelante se adoptará la denominación Arquivologia cuando se haga referencia a los cursos de formación en Brasil.

iii Véase COMISSÃO ESPECIAL DE PRESERVAÇÃO DO ACERVO DOCUMENTAL - CEPAD. A importância da informação e do documento na administração pública brasileira. Brasília: FUNCEP, 1987 y FUNDACIÓN Histórica Tavera. Relatório sobre a situação do patrimônio documental brasileiro. Mesa Redonda Nacional de Arquivos. Rio de Janeiro, 1999.

iv BRASIL. Ministério da Educação e Cultura. Sinopse Estatística do Ensino Superior - 1990. Brasília, ago. 1991.

${ }^{\vee}$ En Brasil los Consejos Profesionales son organizaciones que agregan profesionales de determinada categoría para, entre otras actuaciones, fiscalizar el ejercicio profesional.

vi El Decreto posee el sumario: "Exige registro profissional para reclassificação e ingresso nas categorias funcionais do GrupoArquivo do Serviço Civil do Poder Executivo".

vii Con la ausencia del Consejo Profesional, el archivero deja de tener la obligatoriedad de sacar su registro profesional, revelado por los bajos índices en todo Brasil.

viii La Uni-Rio absorbió el curso promovido por el Archivo Nacional, de modo que se identifica como el primer curso de formación. Véase http://www.unirio.br/arquivologia.

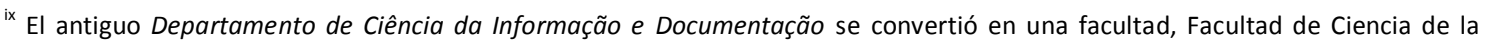
Información, por la Resolución no 10, del Consejo Universitario, de 30 de abril de 2010.

${ }^{x}$ Las informaciones para componer la tabla fueron extraídas de las páginas Web de los cursos siendo que algunas presentan los totales de la carga horaria de los cursos.

xi Para ingresar en el sitio se requiere la invitación de un miembro. Una vez acepta, la persona crea su perfil donde pone las informaciones personales como nombre, fecha de nacimiento, edad, ciudad donde vive, país y otras seleccionadas en un registro previo. Además de los datos personales, es posible incluir amigos y comunidades. Consultado desde julio de 2006 hasta julio de 2008.

xii Las comunidades pueden crearse por temáticas de interés, profesionales u otras, con la condición de tener perfil en el sitio.

xiii Vide las páginas de los cursos de Arquivologia.

${ }^{x i v}$ En portugués, arquivamento.

${ }^{x v}$ Consideramos como formación continuada los cursos realizados posteriores a la graduación. 